\title{
Ab-externo cyclodialysis enhanced trabeculectomy for intractable post-penetrating keratoplasty glaucoma
}

Glaucoma research facility \& clinical services, Dr Rajendra Prasad Centre for Ophthalmic Sciences, All India Institute of Medical Sciences, New Delhi, India

Correspondence: R Sihota, Glaucoma research facility \& clinical services, Dr Rajendra Prasad Centre for Ophthalmic Sciences, Ansari Nagar, New Delhi 110029, India Tel: + 9111 1686485165; Fax: + 911126588919 ; E-mail: rjsihota@ hotmail.com

Received: 29 May 2009 Accepted in revised form: 21 October 2009

Published online:

11 December 2009

\begin{abstract}
Purpose To evaluate the efficacy of cyclodialysis-enhanced Mitomycin c (MMC) trabeculectomy in post-keratoplasty glaucoma. Design Prospective, non-comparative, interventional case series.

Methods A total of 45 eyes of 45 consecutive patients with refractory glaucoma after penetrating glaucoma underwent a cyclodialysis-augmented trabeculectomy with MMC. The visual acuity, intraocular pressure (IOP), corneal clarity, and graft failure were evaluated over a minimum follow-up of 2 years. Results The mean age of the patients was $55.4 \pm 9.4$ years. The cyclodialysis-augmented MMC trabeculectomy procedure resulted in a mean reduction of IOP from $38.9 \pm 3.9 \mathrm{~mm} \mathrm{Hg}$ (95\% confidence interval (CI) 35.9-42.2) at baseline to $11.3 \pm 2.8 \mathrm{~mm} \mathrm{Hg}$ (95\% CI 9.5-12.9), at final follow up $(P=0.002)$. Blebs were avascular, diffuse, and extended posteriorly. Postoperative UBMs revealed the presence of a cyclodialysis with a small associated suprachoroidal effusion and a subconjunctival filtering bleb in all cases.

Conclusions Cyclodialysis-augmented MMC trabeculectomy provides a safe and effective method of lowering IOP in intractable glaucoma following penetrating keratoplasty, without compromising the corneal graft survival and clarity.

Eye (2010) 24, 976-979; doi:10.1038/eye.2009.282; published online 11 December 2009
\end{abstract}

Keywords: keratoplasty; glaucoma; cyclodialysis; mitomycin C trabeculectomy

\section{Introduction}

The incidence of glaucoma after penetrating keratoplasty reportedly varies from 9 to $31 \%$ in the early and from 18 to $35 \%$ in the late postoperative period. ${ }^{1}$ Conventional trabeculectomy has a low success rate in lowering intraocular pressure (IOP), with antimetabolite use causing frequent graft failure. ${ }^{2-4}$ Graft failure rates are high after all kinds of glaucoma surgery. ${ }^{5-8}$

\section{Patients and methods}

Consecutive adult patients having refractory glaucoma for $\geqslant 3$ months after a penetrating keratoplasty underwent ab-externo cyclodialysis enhanced Mitomycin C (MMC) trabeculectomy. Data of patients with $\geqslant 24$ months of follow-up were analysed.

All patients were counselled and an informed consent was taken. The study was approved by our Institutional ethics committee.

Age, gender, particulars of penetrating keratoplasty, baseline and final IOP (pneumotonometry/applanation), graft status, and complications were noted.

Patients who had no perception of light were excluded from the study.

\section{Surgical procedure}

A limbus-based conjunctival flap was raised and a partial thickness rectangular scleral flap $5 \times 4 \mathrm{~mm}$ was dissected. MMC $(0.04 \%)$ was applied intrasclerally for $3 \mathrm{~min}$. The 


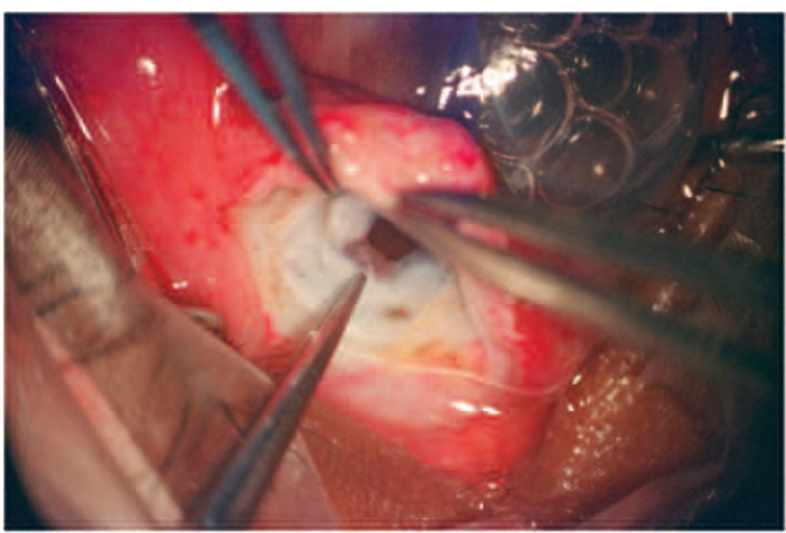

Figure 1 Surgical photograph showing the cyclodialysis with trabeculectomy.

Table 1 Baseline data of eyes that underwent ab-externo cyclodialysis enhanced trabeculectomy

\begin{tabular}{lc}
\hline Variable & Number of eyes \\
\hline Corneal diagnosis & 12 \\
Pseudophakic bullous keratopathy & 11 \\
Aphakic bullous keratopathy & 20 \\
Healed corneal ulcer & 2 \\
Macular corneal dystrophy & \\
& \\
Previous surgery & \\
Combined penetrating keratoplasty + cataract & 35 \\
Cataract surgery & \\
$\quad$ Posterior chamber IOL & 23 \\
$\quad$ Anterior chamber IOL & 7 \\
Aphakia & 5 \\
Re-penetrating keratoplasty & 7 \\
Trabeculectomy & 15 \\
Diode laser cyclophotocoagulation & 15 \\
& \\
Pathogenesis of glaucoma & \\
Peripheral synechial angle closure & \\
Synechiae at the graft-host junction & 39 \\
Chronic uveitis & 35 \\
Secondary open angle glaucoma & 31 \\
\hline
\end{tabular}

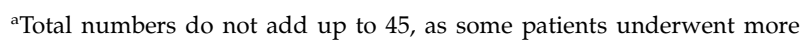
than one previous surgery and some eyes had more than one cause for raised IOP.

scleral spur was identified as the junction between the blue-grey transition zone of the limbus and the white sclera. A 3-mm long, circumferential, deeper corneoscleral block was excised, to include sclera $1 \mathrm{~mm}$ in front and $1 \mathrm{~mm}$ behind the scleral spur. This revealed a millimetre of the ciliary body posteriorly, recognised by its lighter colour and vascularity of the ciliary body surface (Figure 1). A peripheral iridectomy was performed anteriorly and the scleral flap and conjunctiva were sutured. Postoperative therapy included topical steroids, cycloplegics, and antibiotics for 6 weeks.
Success was defined as an IOP between 6 and $20 \mathrm{~mm} \mathrm{Hg}$, without the use of additional antiglaucoma medication/laser/surgery at the last follow-up, with no drop of vision.

Wilcoxon signed-rank test was used to compare the variables. Two-tailed probability values of $<0.05$ were regarded as statistically significant.

\section{Results}

The mean age of the 45 patients was $55.4 \pm 9.4$ years.

There were 28 males and 17 females, $P=0.3$, with a mean follow-up of $28.1 \pm 2.0$ months (95\% CI 24.7-33.2).

The baseline clinical data are presented in Table 1. The glaucoma was multifactorial with peripheral synechial angle closure, synechiae at the graft-host junction, and chronic uveitis seen in these eyes.

The baseline mean IOP was $38.9 \pm 3.9 \mathrm{~mm} \mathrm{Hg}(95 \% \mathrm{CI}$ 35.9-42.2), and at final follow-up after cyclodialysis enhanced MMC trabeculectomy, it was $11.3 \pm 2.8 \mathrm{~mm} \mathrm{Hg}$ (95\% CI 9.5-12.9), $(P=0.002)$. One patient had an IOP of $28 \mathrm{~mm} \mathrm{Hg}$ at $1 \mathrm{month}$, another $20 \mathrm{~mm} \mathrm{Hg}$ at 1 year.

Blebs were avascular, diffuse, and extended posteriorly (Figures $2 \mathrm{a}$ and $\mathrm{b}$ ).

All eyes showed either an improvement in visual acuity or remained stable (Table 2).

One patient developed an endothelial rejection 2 years later. Postoperatively, complications such as graft failure, severe postoperative hypotony, blebitis, or suprachoroidal bleeding were not seen in any case.

A postoperative ultrasound biomicroscopy revealed the presence of a cyclodialysis with minimal suprachoroidal effusion, underlying a subconjunctival filtering bleb in all cases. (Figure 3).

\section{Discussion}

Post-keratoplasty glaucoma is difficult to manage, with the necessity for a consistent decrease of IOP and maintenance of corneal graft clarity. ${ }^{2-8}$

Cyclodialysis, as practiced earlier, used a cyclodialysis spatula passed under the scleral lip to mechanically depress the ciliary body, attempting to thereby separate the ciliary body from the scleral spur. The spatula was further swept without direct observation from side to side to allow disinsertion over $\geqslant 2$ clock hours. The procedure was fraught with unpredictability and complications, especially hypotony and haemorrhage. ${ }^{9,10}$ However, the efficacy of a cyclodialysis was reconfirmed by Johnson et al ${ }^{11}$ who performed a conventional cyclodialysis in rats after experimental 

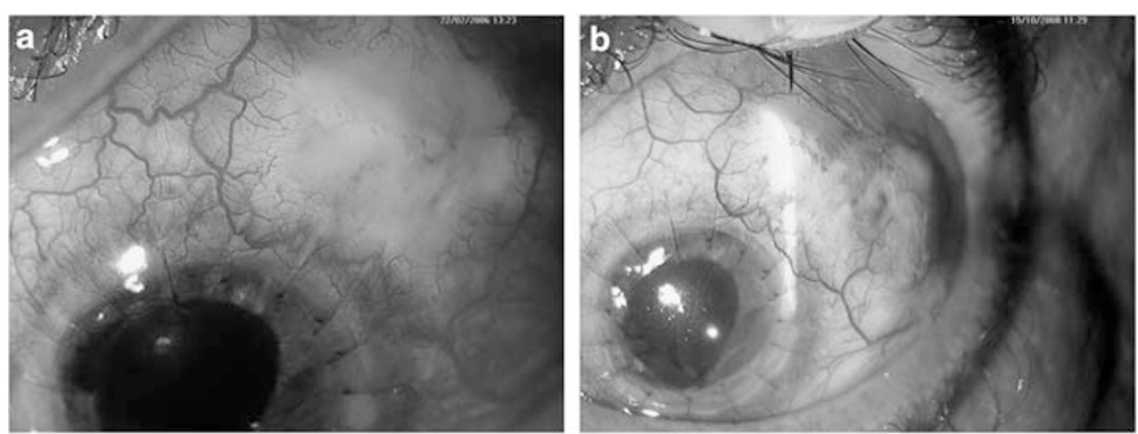

Figure 2 Clinical photograph of the functioning bleb with clear corneal graft after cyclodialysis enhanced trabeculectomy. (a) After 1 year there is a large, posterior, diffusely avascular bleb. (b) After 3 years, subsequent to an episode of endothelial rejection, the bleb is still mildly elevated as evidenced by the configuration of the slit, diffuse, avascular, and functioning.

Table 2 Preoperative and postoperative data of eyes that underwent ab-externo cyclodialysis enhanced trabeculectomy

\begin{tabular}{|c|c|c|}
\hline Variable & Baseline & Final follow-up \\
\hline IOP (mm Hg) & $39.6 \pm 3.9$ & $11.3 \pm 2.8$ \\
\hline \multicolumn{3}{|l|}{$\begin{array}{l}\text { Vision (Snellens } \\
\text { acuity) }\end{array}$} \\
\hline $20 / 200-20 / 40$ & 18 & No change $(n=18)$ \\
\hline$<20 / 200$ & 27 & $\begin{array}{l}\text { Improved to } 20 / 200(n=8) \\
\text { Stable/no change }(n=19)\end{array}$ \\
\hline \multirow{2}{*}{$\begin{array}{l}\text { Graft clarity } \\
\text { (grade 1-4) }\end{array}$} & Grade $1 n=5$ & Improved $(n=24)$ \\
\hline & $\begin{array}{l}\text { Grade } 2 n=12 \\
\text { Grade } 3 n=16 \\
\text { Grade } 4 n=12\end{array}$ & Stable $(n=21)$ \\
\hline \multirow{2}{*}{$\begin{array}{l}\text { Antiglaucoma } \\
\text { medications }\end{array}$} & \multirow{2}{*}{$\begin{array}{l}45 \text { (Maximal } \\
\text { medical therapy) }\end{array}$} & 43 eyes: Nil \\
\hline & & $\begin{array}{l}1 \text { eye: } 2 \text { topical medications } \\
1 \text { eye: } 1 \text { topical medication }\end{array}$ \\
\hline Graft failure & 27 & 27 \\
\hline Follow-up period & - & $\begin{array}{l}28.1 \pm 2.0 \text { months } \\
(95 \% \text { CI } 24.7-33.2)\end{array}$ \\
\hline
\end{tabular}

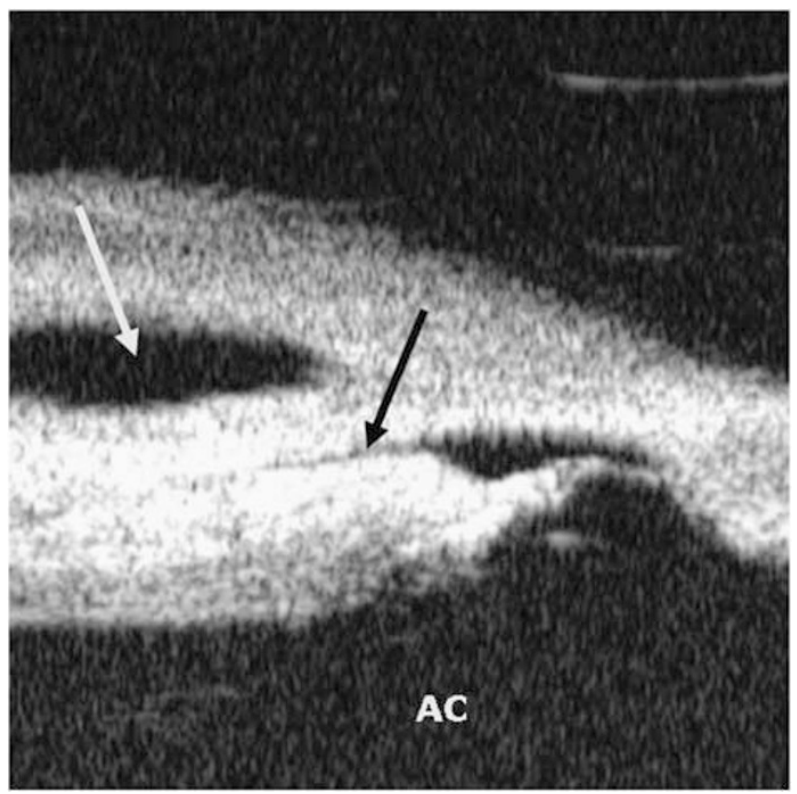

Figure 3 Ultrasound biometry of the bleb showing subconjunctival drainage (white arrow) and an underlying suprachoroidal cyclodialysis cleft (black arrow).

Table 3 Review of post-keratoplasty glaucoma studies

\begin{tabular}{|c|c|c|c|c|c|}
\hline Author/year & Procedure & $\begin{array}{c}\text { Number } \\
\text { of eyes }\end{array}$ & $\begin{array}{l}\text { Mean duration } \\
\text { of follow-up } \\
\text { (months) }\end{array}$ & IOP control (\%) & $\begin{array}{c}\text { Graft failure } \\
\text { occurring subsequent } \\
\text { to intervention (\%) }\end{array}$ \\
\hline Gilvarry et $a l^{2}$ (1989) & Trabeculectomy & 35 & 36 & 50.5 & 51 \\
\hline Ayyala et al $l^{7}(1998)$ & Trabeculectomy with MMC & 17 & $23 \pm 13$ & 77 & 11.7 \\
\hline Figuerido et al ${ }^{13}$ (1996) & Trabeculectomy with MMC & 9 & 16 & NA & 22.2 \\
\hline \multirow{2}{*}{ Ishioka M et $a l^{3}(2000)$} & Trabeculectomy with MMC & 34 & $22.3 \pm 10.3$ & 73 & 30.8 \\
\hline & Trabeculectomy without MMC & & $22.3 \pm 10.3$ & 25 & 62.5 \\
\hline Wu Dunn D ${ }^{4}(1999)$ & $\begin{array}{l}\text { Combined PK + trabeculectomy } \\
\text { with MMC }\end{array}$ & 24 & 24 & 50 & 25 \\
\hline Kwon et $a l^{5}$ (2001) & GDD & 55 & $34(8-74)$ & 82 & 61.8 \\
\hline Alvarenga et $a l^{14}$ (2004) & GDD & 40 & $\begin{array}{l}\text { December 1986- } \\
\text { September } 2002\end{array}$ & 63.1 & 74.2 \\
\hline Shah P et al ${ }^{16}$ (2001) & Cyclodiode & 28 & $30.5(18-38)$ & 79 & $\begin{array}{l}\text { 16-opacification, } \\
\text { 37-failure/rejection }\end{array}$ \\
\hline This study 2009 & Cyclodialysis enhanced trabeculectomy & 45 & $28.1 \pm 2.0$ & 95.6 & 0 \\
\hline
\end{tabular}


IOP elevation, and showed a $40 \%$ reduction in IOP.

We evaluated a limited ab-externo cyclodialysis performed under direct vision as part of an MMC trabeculectomy. Disinsertion of the ciliary body from its scleral attachment opens up the potential suprachoroidal space, exploiting the resorptive capacity of the choroid. UBM pictures show drainage from both the subconjunctival and suprachoroidal pathways. In our series, the IOP was maintained below $15 \mathrm{~mm} \mathrm{Hg}$ in all but two patients, without any antiglaucoma medications. The blebs were relatively avascular, diffuse, and extended posteriorly. In our study, there was no decrease in graft clarity and no graft failure after the surgery in any eye for up to 2 years. This could be because the corneoscleral block was well away from the graft edge, and the bleb was positioned more posteriorly.

In literature, post-keratoplasty patients have responded poorly to all surgeries, both in terms of IOP control, as well as graft failure, due to extensive peripheral anterior synechiae, limbal vascularisation, uveitis, and extremely shallow anterior chambers (Table 3). ${ }^{1-5,7,12-18}$

The limitation of our study was the absence of a control group, however, 30 of the 45 eyes had previous, failed glaucoma procedures.

In conclusion, an ab-externo cyclodialysis enhanced MMC trabeculectomy maintained or improved graft clarity besides achieving the long-term, low 'target' IOP necessary to control refractory post-penetrating keratoplasty glaucoma.

\section{Summary}

What was known before

- Cyclodialysis was effective but was unpredictable and prone to complications.

\section{What this study adds}

- Limited cyclodialysis as part of an augmented trabeculectomy provides significant lowering of IOP without the complications.

\section{Conflict of interest}

The authors declare no conflict of interest.

\section{References}

1 Ayyala RS. Penetrating keratoplasty and glaucoma - major review. Survey Ophthalmol 2000; 45: 91-105.
2 Gilvarry AME, Kirkness CM, Steele ADM, Rice NS, Ficker LA. The management of post keratoplasty glaucoma by trabeculectomy. Eye 1989; 3: 713-718.

3 Ishioka M, Shimazaki J, Yamagami J, Fujishima $H$, Shimmura S, Tsubota K. Trabeculectomy with mitomycin C for post-keratoplasty glaucoma. Br J Ophthalmol 2000; 84: 714-717.

4 Wu Dunn D, Alfonso E, Palmberg PF. Combined penetrating keratoplasty and trabeculectomy with mitomycin C. Ophthalmology 1999; 106: 396-400.

5 Kwon YH, Taylor JM, Hong S, Honkanen RA, Zimmerman $\mathrm{MB}$, Alward WL et al. Long term results of eyes with penetrating keratoplasty and glaucoma drainage tube implant. Ophthalmology 2001; 108: 272-278.

6 Arroyave CP, Scott IU, Fantes FE, Fener WJ, Murray TG. Corneal graft survival and intraocular pressure control after penetrating keratoplasty and glaucoma drainage device implantation. Ophthalmology 2001; 108: 1978-1985.

7 Ayyala RS, Pieroth L, Vinals AF, Goldstein MH, Schuman JS, Netland PA et al. Comparison of mitomycin C trabeculectomy, glaucoma drainage device implants and laser neodymium YAG cyclophotocoagulation in the management of glaucoma after penetrating keratoplasty. Ophthalmology 1998; 105: 1550-1556.

8 Foulks GN. Glaucoma associated with penetrating keratoplasty. Ophthalmology 1987; 94: 871-874.

9 Sedan J. On excessive hypotony following cyclodialysis. Bull Soc Ophthalmol Fr 1966; 66(10): 959-971.

10 Vorosmarthy D. Prophylactic measures for the lessening of the risk of haemorrhage in cyclodialysis. Klin Monatsbl Augenheilkd 1966; 148(3): 369-374.

11 Johnson EC, Cepurna WO, Jia L, Morrison JC. The use of cyclodialysis to limit exposure to elevated intraocular pressure in rat glaucoma models. Exp Eye Res 2006; 83(1): 51-60.

12 Insler MS, Cooper HD, Kastl PR. Penetrating keratoplasty with trabeculectomy. Am J Ophthalmol 1985; 100: 593-595.

13 Figuerido RS, Araujo SV, Cohen EJ, Rapuano CJ, Katz LJ, Wilson RP. Management of coexisting corneal disease and glaucoma by combined penetrating keratoplasty and trabeculectomy with mitomycin C. Ophthalmic Surg Lasers 1996; 27: 903-909.

14 Alvarenga LS, Mannis MJ, Brandt JD, Schwab IR, Lim MC. The long term results of keratoplasty in eyes with a glaucoma drainage device. Am J Ophthalmol 2004; 138: 200-205.

15 Binder PS, Abel Jr R, Kaufman HE. Cyclocryotherapy for glaucoma after penetrating keratoplasty. Am J Ophthalmol 1975; 79: 489-492.

16 Kirkness CM, Ling Y, Rice NS. The use of silicon drainage tubing to controls post-keratoplasty glaucoma. Eye 1988; 2: 583-590.

17 Shah P, Lee GA, Kirwan JK, Bunce C, Bloom PA, Ficker LA et al. Cyclodiode photocoagulation for refractory glaucoma after penetrating keratoplasty. Ophthalmology 2001; 108: 1986-1991.

18 Jordan JF, Dietlein TS, Dinslage S, Luke C, Konen W, Krieglstein GK. Cyclodialysis ab interno as a surgical approach to intractable glaucoma. Graefes Arch Clin Exp Ophthalmol 2007; 245: 1071-1076. 